\title{
A Novel Alloy Development Approach: Biomedical Equiatomic Ta-Nb-Ti Alloy
}

\author{
Maximilian Regenberg ${ }^{1, *}$, Janett Schmelzer ${ }^{1}$, Georg Hasemann $\left.{ }^{1}{ }^{(}\right)$, Jessica Bertrand ${ }^{2}\left(\mathbb{C}\right.$ and Manja Krüger ${ }^{1}(\mathbb{D}$ \\ 1 Institute of Materials and Joining Technology, Otto-von-Guericke University Magdeburg, Universitätsplatz 2, \\ 39106 Magdeburg, Germany; Janett.schmelzer@ovgu.de (J.S.); georg1.hasemann@ovgu.de (G.H.); \\ manja.krueger@ovgu.de (M.K.) \\ 2 Department of Orthopedic Surgery, Otto-von-Guericke University Magdeburg, Leipziger Str. 44, \\ 39120 Magdeburg, Germany; Jessica.bertrand@med.ovgu.de \\ * Correspondence: Maximilian.regenberg@ovgu.de; Tel.: +49-391-67-54505
}

Citation: Regenberg, M.; Schmelzer, J.; Hasemann, G.; Bertrand, J.; Krüger, M. A Novel Alloy Development Approach: Biomedical Equiatomic Ta-Nb-Ti Alloy. Metals 2021, 11, 1778. https://doi.org/10.3390/met11111778

Academic Editors: Oleg N. Senkov,

Panagiotis (Panos) Tsakiropoulos and Jean-Philippe Couzinie

Received: 23 September 2021

Accepted: 2 November 2021

Published: 4 November 2021

Publisher's Note: MDPI stays neutral with regard to jurisdictional claims in published maps and institutional affiliations.

Copyright: (c) 2021 by the authors. Licensee MDPI, Basel, Switzerland. This article is an open access article distributed under the terms and conditions of the Creative Commons Attribution (CC BY) license (https:/ / creativecommons.org/licenses/by/ $4.0 /)$.

\begin{abstract}
In the present manuscript, we report on the properties of an equiatomic Ta- $\mathrm{Nb}-\mathrm{Ti}$ alloy as the basis for a novel, biomedical, multi-component alloy development. The alloy was produced using an arc melting furnace under Ar atmosphere, metallographically prepared, and investigated respectively. Furthermore, the alloy produced, as well as samples of elemental $\mathrm{Ta}, \mathrm{Nb}$, alloy Co$28 \mathrm{Cr}-6 \mathrm{Mo}$, and alloy Ti-6Al-4V, were prepared with defined 1200 grit SiC grinding paper. The topography of the surfaces was evaluated using confocal microscopy and contact angle measurements subsequently. Afterwards, the biocompatibility of the novel alloy Ta-Nb-Ti was evaluated by means of cell (osteoblast) attachment as well as monocyte inflammatory response analysis. First results indicate competitive osteoblast attachment, as well as comparable expressions of fibrosis markers in comparison to conventionally used biomedical materials. In addition, the Ta- $\mathrm{Nb}-\mathrm{Ti}$ alloy showed a markedly reduced inflammatory capacity, indicating a high potential for use as a prospective biomedical material.
\end{abstract}

Keywords: high-entropy alloys; refractory elements; biocompatibility; biomedical materials; cell cultivation

\section{Introduction}

The modern material class of equiatomic multi-component alloys, especially highentropy alloys (HEAs), has gained tremendous attention in the scientific community over recent years [1-3], which can be attributed to two main reasons. Firstly, the new concept of combining several elements (at least 5 principal elements with concentrations between 5 and 35 at. \% [4]) in contrast to conventional alloys, mostly containing only two or three elements in addition to the main alloy constituent, results in a broad variety of possible combinations, thus leading to completely novel alloys with exceptional properties. Secondly, recently developed refractory metal based high-entropy alloys (RHEAs) have shown properties that are superior to those of current state-of-the-art alloys, which are attributed to several unique thermodynamic effects [1,5]. However, besides the outstanding mechanical properties, abrasion resistance, and thermal resistance, a vast variety of chemical elements used in RHEAs also belong to the category of biocompatible elements (highlighted in Figure 1), hence leading to potentially new biomedical materials [6-8]. 


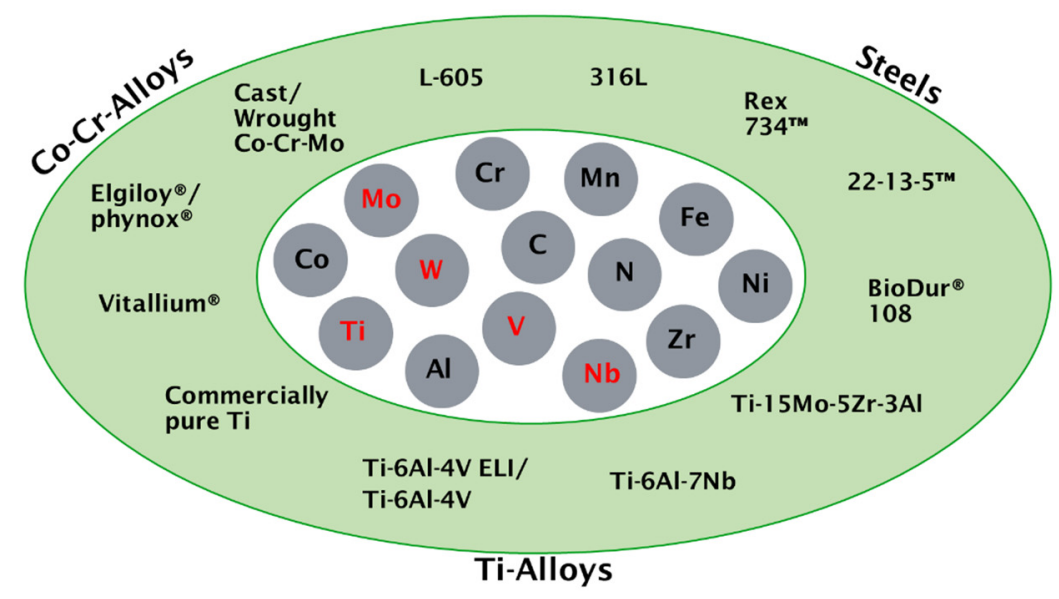

Figure 1. Schematic representation of state-of-the-art biomaterials data from [9-13] and the corresponding chemical elements; refractory metals of potential interest are highlighted.

To meet the demands for biomedical applications, specifically for implant materials, three main criteria must be fulfilled: Excellent mechanical properties (regarding the force transmission between implant and bone), corrosion resistance (prevention of corrosive damage to the implant), and biocompatibility (no tissue damage by the implant material or by corrosive/abrasive particles) [13].

The present study meets these targets on the basis of previous investigations regarding Mo-Nb-V-W-Ti high-entropy alloys [14], which have confirmed promising mechanical properties. Furthermore, several publications concerning the corrosive capabilities and degradation resistance [15-17] are considered to support our theories. In particular, alloys either based on, or at least containing high fractions of refractory metals, have shown favorable properties with regard to potential use in the field of biomedical materials [18-20]. Primarily, this can be attributed to their resilient character in general, meaning high melting temperatures, high hardness, oxidation resistance, etc. [21], as well as the good biocompatibility of the majority of refractory elements [22,23], leading to a desirable combination of component properties.

However, in consideration of this background and due to the excellent biocompatibility of the constituents $[9,10]$, an equiatomic composition of $\mathrm{Ta}, \mathrm{Nb}$, and $\mathrm{Ti}$ as a multi-component base alloy was chosen for the experiments.

\section{Materials and Methods}

\subsection{Production, Preparation and Analysis of the Substrate Materials}

For sample production, high purity elemental chips or flakes of $\mathrm{Ta}(99.9 \%), \mathrm{Nb}(99.9 \%)$ and $\mathrm{Ti}(99.6 \%)$ were used as starting materials and were carefully weighed. The alloying process was carried out in a conventional arc-melting device under Ar atmosphere. Each sample was re-melted five times to ensure sufficient homogeneity. Afterwards, the produced oblong-shaped (due to the use of an elongated mold) melted product was cut into $2 \mathrm{~mm}$ thick slices by means of electric discharge machining (EDM). One slice was used for microstructural analysis and thus metallographically prepared (grinded with $\mathrm{SiC}$ paper to a 1000 grit, polished using $3 \mu \mathrm{m}$ and $1 \mu \mathrm{m}$ diamond suspension and finished using colloidal silica suspension subsequently) afterwards. The remaining slices were cleaned from the EDM-burr and grinded to a defined grit size of 1200 . To identify the phases present, X-ray diffraction analysis (XRD) were performed on a X'Pert Pro (PANalytical, Almelo, The Netherlands), using Co K $\alpha$ radiation. Microstructural observations were carried out by means of scanning electron microscopy (ESEM XL30 FEG, FEI, Hillsboro, OR, USA), using back-scattered electron (BSE) imaging with the following setup: Centaurus BSE detector with an acceleration voltage of $25 \mathrm{kV}$, magnification of $100 \times$ and a working distance of $11.4 \mathrm{~mm}$. To determine the elemental distribution and the chemical composition of the alloy, $(\mathrm{Si}(\mathrm{Li}))$-detector energy-dispersive $\mathrm{X}$-ray spectroscopy (EDS) analysis equipped with 
Genesis software (EDAX, Mahwah, NJ, USA) was conducted. The surface roughness of the samples was analyzed by using a confocal microscope ( $\mu$ surf expert, NanoFocus AG, Oberhausen, Germany) on a surface area of $322 \times 321 \mu \mathrm{m}$, using a $20 \times$ magnification objective with a lateral $(x, y)$ measuring range of $800 \mu \mathrm{m}$. In addition, the contact angles of the surfaces were determined using an optical contact angle and drop contour analyzer (OCA 20, DataPhysics Instruments GmbH, Filderstadt, Germany) and the corresponding software (SCA 20, DataPhysics Instruments GmbH, Filderstadt, Germany). To characterize the hardness of the alloy produced, microhardness analysis was carried out by means of 20 HV0.1 indents in a square grid across the entire sample surface, using an automatic hardness tester VH3300 (Wilson/Buehler, Esslingen, Germany). Furthermore, to examine and evaluate the biocompatibility of the alloy $\mathrm{Ta}-\mathrm{Nb}-\mathrm{Ti}$, cell cultivation experiments were carried out on the surface of the specimens and compared to state-of-the-art biomaterials, such as wrought alloy Co-28Cr-6Mo or alloy Ti- $6 \mathrm{Al}-4 \mathrm{~V}$, as well as to samples of pure $\mathrm{Ta}$, $\mathrm{Nb}$, and Ti.

\subsection{Osteoblast (SaOs Cells) Attachment Assay}

SaOs- 2 cells were seeded with a cell number of $0.3 \times 10^{5}$ in $100 \mu \mathrm{L}$ for $2 \mathrm{~h}$ on the platelets to let the cells attach to the surface. Afterwards, $1 \mathrm{~mL}$ DMEM (Dulbecco Modified Eagle Medium) culture medium with the addition of 10\% FCS (fetal calf serum) and 1\% penicillin/streptomycin was pipetted into each well to cover the platelets with cells. On the following day, the cells were fixed with $4 \%$ formaldehyde and washed three times with PBS (phosphate buffered saline). Subsequently, the samples were incubated with $200 \mu \mathrm{L}$ of a PBS with Phalloidin Alexa Fluor 488 (1:100) and DAPI (4',6-Diamidino-2-phenylindol) (1:1000) in the dark for $15 \mathrm{~min}$ (room temperature, RT). Excess staining solution was removed by washing three times with PBS. The samples were stored at $4{ }^{\circ} \mathrm{C}$ in the dark until further use. Imaging was performed with a Zeiss fluorescence microscope (Axio Observer.Z1, Zeiss, Jena, Germany) at 630× magnification. Fluorescence was detected at the wavelengths $488 \mathrm{~nm}$ (Phalloidin green) and $454 \mathrm{~nm}$ (DAPI blue). Four images were taken of each sample. For evaluation, the area of one cell (green fluorescence) was divided by the size of the nucleus (blue fluorescence) using ImageJ.

\subsection{Monocyte Inflammatory Reaction Test}

Mono-mac-6 cells (MM6) are a human acute monocytic leukemia derived cell line. These cells were cultured in a density $0.5 \times 10^{6}$ in $100 \mu \mathrm{L}$ on the different alloy specimens for $24 \mathrm{~h}$. Subsequently, the cells were lysed using TRIZol and RNA (ribonucleic acid) was isolated for quantitative RT-PCR (reverse transcription polymerase chain reaction).

\subsection{RNA Extraction, cDNA Synthesis, Real-Time RT-PCR}

Total RNA was extracted from cells using TRIZol reagent (Invitrogen, Thermo Fisher Scientific). Thus, $1 \mathrm{ng}$ of total RNA from each sample was reverse transcribed using HighCapacity cDNA (complementary deoxyribonucleic acid) Reverse Transcription Kit (Applied Biosystems) using random primers. Quantitative PCR (polymerase chain reaction) was performed with SYBR green using Applied Biosystems ${ }^{\mathrm{TM}}$ Quantstudio 6 (Thermo Fisher Scientific). The following primers were used at an annealing temperature of $60^{\circ} \mathrm{C}$ :

hIL-1 $\beta$ For (human interleukin-1 $\beta$ ):

ACAGATGAAGTGCTCCTTCCA

hIL-1 $\beta \_$Rev:

GTCGGAGATTCGTAGCTGGAT

hTNF- $\alpha \_$For (human tumor necrosis factor- $\alpha$ ):

CAGCCTCTTCTCCTTCCTGAT

hTNF- $\alpha \_$Rev:

GCCAGAGGGCTGATTAGAGA

hIL-6_For (hyper interleukin-6):

CTTTTGGAGTTTGAGGTATACCTAG 
hIL-6_Rev:

GCTGCGCAGAATGAG AGTAGTTGT

hGAPDH_for (human Glyceraldehyde-3-phosphate dehydrogenase):

CCCACTCCTCCACCTTTGAC

hGAPDH_rev:

AGCCAAATTCGTTGTCATACCAG

Absolute quantification was carried out using standard curves. Target gene expression was normalized to GAPDH.

\subsection{Cleaning and Sterilization of the Samples}

Before in vitro incubation, all samples were cleaned by incubation for $30 \mathrm{~min}$ in $10 \mathrm{~mL}$ of RIPA (radioimmunoprecipitation assay) buffer at room temperature under sonication and rinsed in distilled water. Afterwards, the platelets were incubated with Trypsin for $30 \mathrm{~min}$ at $37^{\circ} \mathrm{C}$ under sonication. The specimens were rinsed with distilled water and incubated in $70 \%$ ethanol. For sterilization, the platelets were flamed and placed under UV (ultraviolet) light for $24 \mathrm{~h}$. Applying this cleaning procedure, the specimens were reused for the repetition of experiments.

\subsection{Statistical Analysis of the Biocompatibility Experiments}

If not stated otherwise, the data are presented as mean \pm standard deviation (SD). The Friedman test was applied to test for statistical significance. The level of significance was set at $p<0.05$ for all statistical tests. Statistical analysis was performed using GraphPad Prism (Version 7, GraphPad Software, San Diego, CA, USA).

\section{Results \& Discussion}

\subsection{Alloy Design}

In order to provide a comparable base with regard to the alloy design of $\mathrm{Ta}-\mathrm{Nb}-\mathrm{Ti}$, the thermodynamic and geometrical calculations for high-entropy materials were used. Although the equiatomic alloy $\mathrm{Ta}-\mathrm{Nb}$-Ti reported on does not yet meet all criteria of the HEA definition [4], it should be noted that the current design is a base for further research. As it is widely reported in the literature (f.e. [24]), the formation of a solid solution phase (SS) is determined by the Gibbs free energy $\left(\Delta \mathrm{G}_{\mathrm{mix}}\right)$, hence a combination of the present enthalpy of mixing $\left(\Delta \mathrm{H}_{\mathrm{mix}}\right)$, the temperature $(\mathrm{T})$, and the entropy of mixing $\left(\Delta S_{\text {mix }}\right)$ [5,24-26]. Furthermore, the solid solution parameter $(\Omega)$, representing the ratio between entropy and enthalpy, and the difference in atomic radii of the elements involved $(\delta)$ were considered $[27,28]$. To put the results of the calculations in perspective and to demonstrate the potential of the alloy $\mathrm{Ta}-\mathrm{Nb}$ - $\mathrm{Ti}$, the values are compared to data from the RHEA group in Table 1 and depicted as $\Delta \mathrm{H}_{\mathrm{mix}}-\delta$ plot in Figure 2. The diagram demonstrates the theoretical tendency of a HEA to either form a solid solution phase or an amorphous phase (cf. bulk metallic glasses) in the as-cast condition. Previous works $[29,30]$ suggest that the delineation of aforementioned phase formations follows a rather simple rule: positive or slightly negative $\Delta \mathrm{H}_{\text {mix }}$ values $\left(\Delta \mathrm{H}_{\text {mix }}>\sim-11.6 \mathrm{~kJ} / \mathrm{mol}\right)$ and moderate $\delta$ values $(\delta<\sim 0.066)$ support the formation of the solid solution phase, whilst a more negative $\Delta \mathrm{H}_{\text {mix }}\left(\Delta \mathrm{H}_{\text {mix }}<\sim-12.2 \mathrm{~kJ} / \mathrm{mol}\right)$ and corresponding higher $\delta(\delta>\sim 0.064)$ benefit the formation of an amorphous phase. Hence being a key feature of HEAs, the formation of a single-phased structure is desired in the present study.

It should be mentioned here that a third region with regard to the formation of intermetallic phases (especially after heat treatment experiments) is not added in Figure 2 in this publication, firstly for the sake of simplicity and secondly due to the present lack of heat treatment results regarding the alloy developed. However, this can be found frequently in corresponding literature [30,31]. 
Table 1. Results of the thermodynamic and geometrical calculations of alloy $\mathrm{Ta}-\mathrm{Nb}-\mathrm{Ti}$, using the equations presented in [24-28] and comparison with other high-entropy alloys for potential biomedical use.

\begin{tabular}{|c|c|c|c|c|c|}
\hline Alloy & $\Delta \mathrm{S}_{\text {mix }}, \mathrm{J} \cdot \mathrm{K}^{-1} \cdot \mathrm{mol}^{-1}$ & $\Delta \mathrm{H}_{\text {mix }}, \mathrm{kJ} \cdot \mathrm{mol}^{-1}$ & $\delta, \%$ & $\Omega$ & References \\
\hline $\mathrm{Ta}-\mathrm{Nb}-\mathrm{Ti}$ & 9.13 & 1.3 & 1.5 & 18.2 & this work \\
\hline MoNbTaTiZr & 13.38 & -1.8 & 5.9 & 19.7 & {$[16,18]$} \\
\hline TiZrHfNbTa & 13.38 & 2.7 & 5.5 & 12.4 & {$[18,22]$} \\
\hline TiNbTaZrW & 13.38 & -3.2 & 5.8 & 11.5 & [18] \\
\hline $\mathrm{Ti}_{2 \cdot 6} \mathrm{NbTaZrMo}$ & 12.57 & -1.2 & 5.2 & 26.4 & [32] \\
\hline $\mathrm{TiNbTa}_{0.2} \mathrm{ZrMo}$ & 12.57 & -2.3 & 6.4 & 13.4 & {$[32]$} \\
\hline $\mathrm{TiNbTaZr}_{2.6} \mathrm{Mo}$ & 12.57 & -0.9 & 6.8 & 36.1 & [32] \\
\hline $\mathrm{TiNbTaZrMo}_{0.2}$ & 12.57 & 1.3 & 5.5 & 24.2 & [32] \\
\hline
\end{tabular}

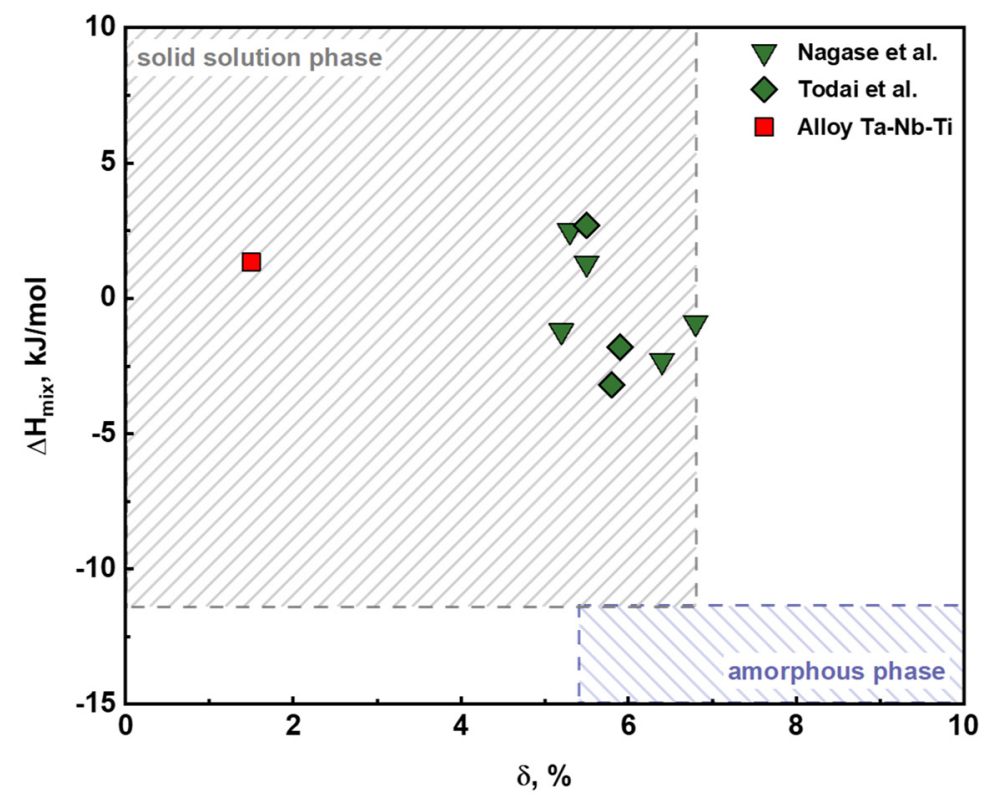

Figure 2. Calculated $\Delta \mathrm{H}_{\text {mix }}-\delta$ plot, focusing on the solid solution phase section and comparing base alloy Ta-Nb-Ti to other relevant Bio-HEAs, from current investigations, data from [16,18,22,32].

\subsection{X-ray Diffraction and EDS Analysis of the Ta-Nb-Ti Alloy}

$\mathrm{XRD}$ analysis of the Ta- $\mathrm{Nb}-\mathrm{Ti}$ alloy was carried out using a $2-\theta$-range from $30^{\circ}$ to $150^{\circ}$ and the results are displayed by means of the relative intensity of the reflexes obtained (Figure 3a). The results indicate a single-phase body centered cubical (bcc) crystal structure with an Im-3m space group. However, Rietveld refinement revealed the presence of two slightly different modifications of the lattice parameters (Im-3m I: a = 3.287 $\AA$; Im-3m: $\mathrm{a}=3.291 \AA$ ). This is in good agreement with the results of the BSE microstructural analysis, depicted in Figure 3b, which shows a dendritic structure with clearly distinguished interdendritic regions (dark regions).

The difference in dendritic size, reaching from very pronounced and branched dendritic crystals in the upper section (with a roughly estimated dendritic arm spacing (DAS) of 10-20 $\mu \mathrm{m}$ ), to a more coarse and bulky formation (no DAS measurements possible) in the lower region of the cross section, depicted in Figure $3 b$, can be attributed to the arc-melting procedure. The process related cooling rates are not constant, thus resulting in different solidification rates of the alloy $[33,34]$. The observed segregation is attributed to the difference in melting temperatures of the components, thus solidifying subsequently [5]. EDS analysis by means of element mappings (Figure 4) indicated a higher fraction of high melting Ta in the dendritic crystals, whilst the lower melting Ti was enriched in the interdendritic regions. $\mathrm{Nb}$ exhibits an intermediate melting temperature in the alloying composition, thus being 
present in the dendrites, as well as predominantly in the interdendritic regions. However, it is expected that long-term heat treatment will reduce the segregation effects [9].
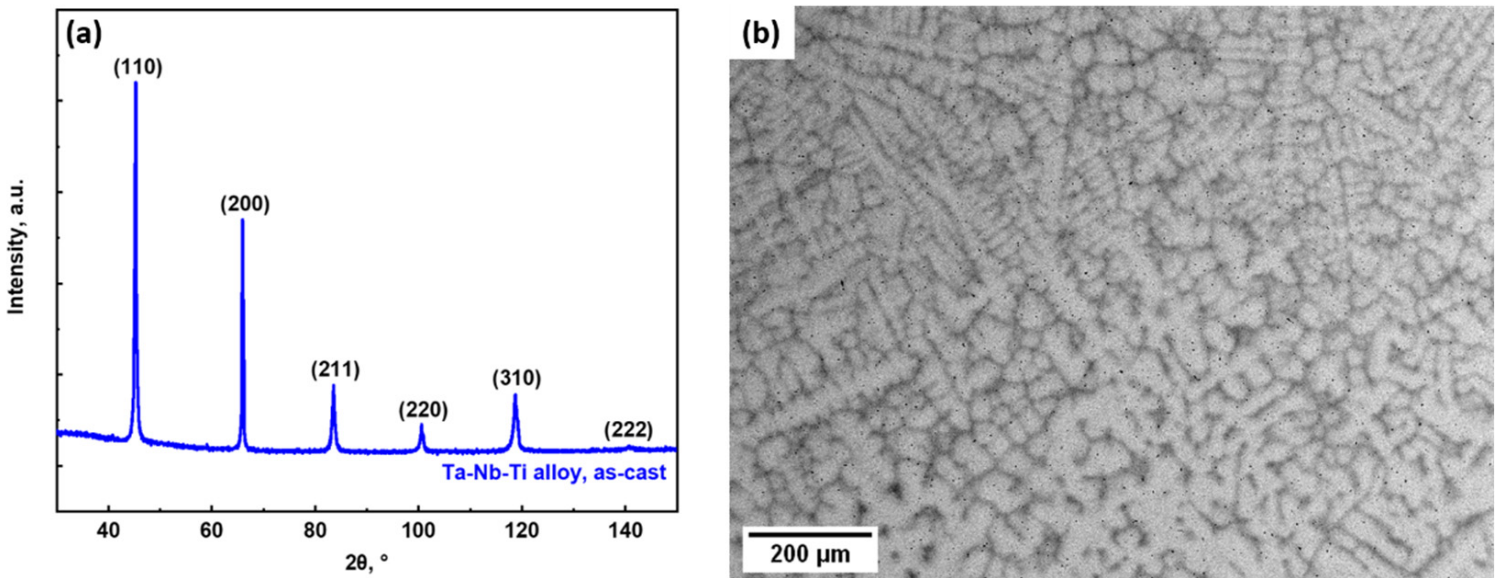

Figure 3. (a) XRD pattern of the Ta-Nb-Ti alloy in the as-cast condition. (b) SEM backscattered electron (BSE) image of the alloy Ta-Nb-Ti.
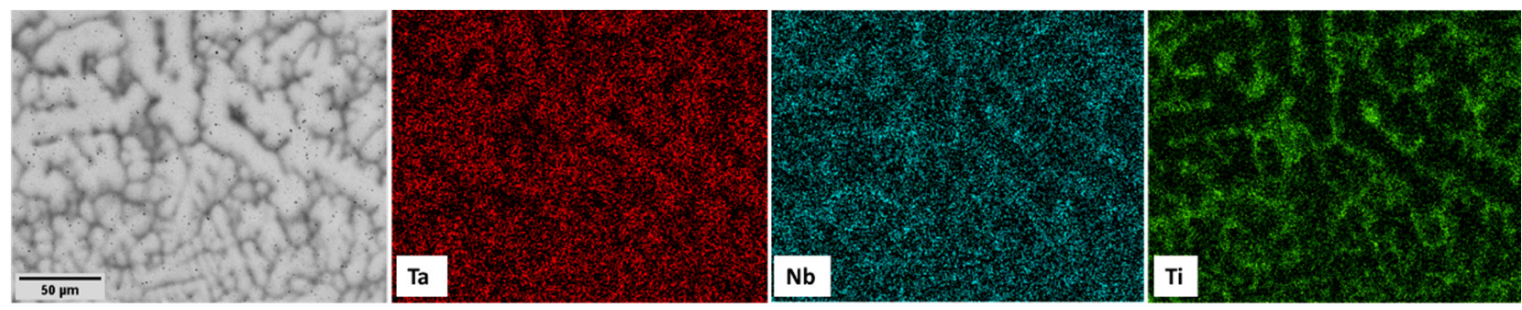

Figure 4. EDS mappings of alloy Ta-Nb-Ti.

\subsection{Surface Preparation and Validation of the Samples}

It has been widely investigated that the surface condition of endoprostheses plays a decisive role regarding cell adhesion and proliferation [35-38]. However, to determine and evaluate the interaction between the material and the attached tissue (rather than the cells and different surface structures) and to obtain a comparable reference value, all samples were manually grinded with a 1200 grit $\mathrm{SiC}$ grinding paper and investigated in that condition. For better handling, the specimens were mounted in cold embedding agent Technovit 4071 (Kulzer, Wehrheim, Germany). After successful preparation of the samples for the cell cultivation experiments, the embedding material was cracked and removed from the metallic samples.

\subsubsection{Microhardness Analysis in Comparison to Competitive Implant Materials}

The hardness values are displayed and compared in Figure 5. It is noticeable that the hardness of alloy Ta- $\mathrm{Nb}$ - $\mathrm{Ti}$ is significantly lower than the values obtained from pure Titanium, however, higher than pure Niobium and comparable to Tantalum. This could be explained by the larger $\mathrm{Ta}$ - and $\mathrm{Nb}$-rich dendrites, thus having a higher impact on the hardness development of the microstructure, compared to the smaller Ti-rich fractions in the interdendritic area. However, compared to the hardness values of the alloys Co- $28 \mathrm{Cr}$ $6 \mathrm{Mo}$ and Ti-6Al-4V, the results obtained from alloy Ta-Nb-Ti are significantly lower. This is caused by the different types of alloy-specific microstructure and resulting strengthening effects (face-centered cubic (fcc) $\gamma$-phase with dispersed carbides regarding the Co-Cr-Mo alloys and the two phase $\alpha-\beta$ structure ( $\alpha$-Ti: hexagonal closest packed, hcp; $\beta$-Ti: bcc) concerning Ti-6Al-4V alloys) [37,39-41]. In general, the obtained hardness results show an opposing trend compared to the results of the OCA tests, as well as the surface roughness analysis. This coherence is based on the fact that if a consistent force is applied on the 
samples for the same time during preparation (grinding), the material with the lowest hardness undergoes the strongest abrasion and deformation, hence resulting in a rough surface. The samples exhibiting higher hardness values, however, have a smoother surface. These circumstances must be considered when the samples are compared with regard to cell adhesion and proliferation.

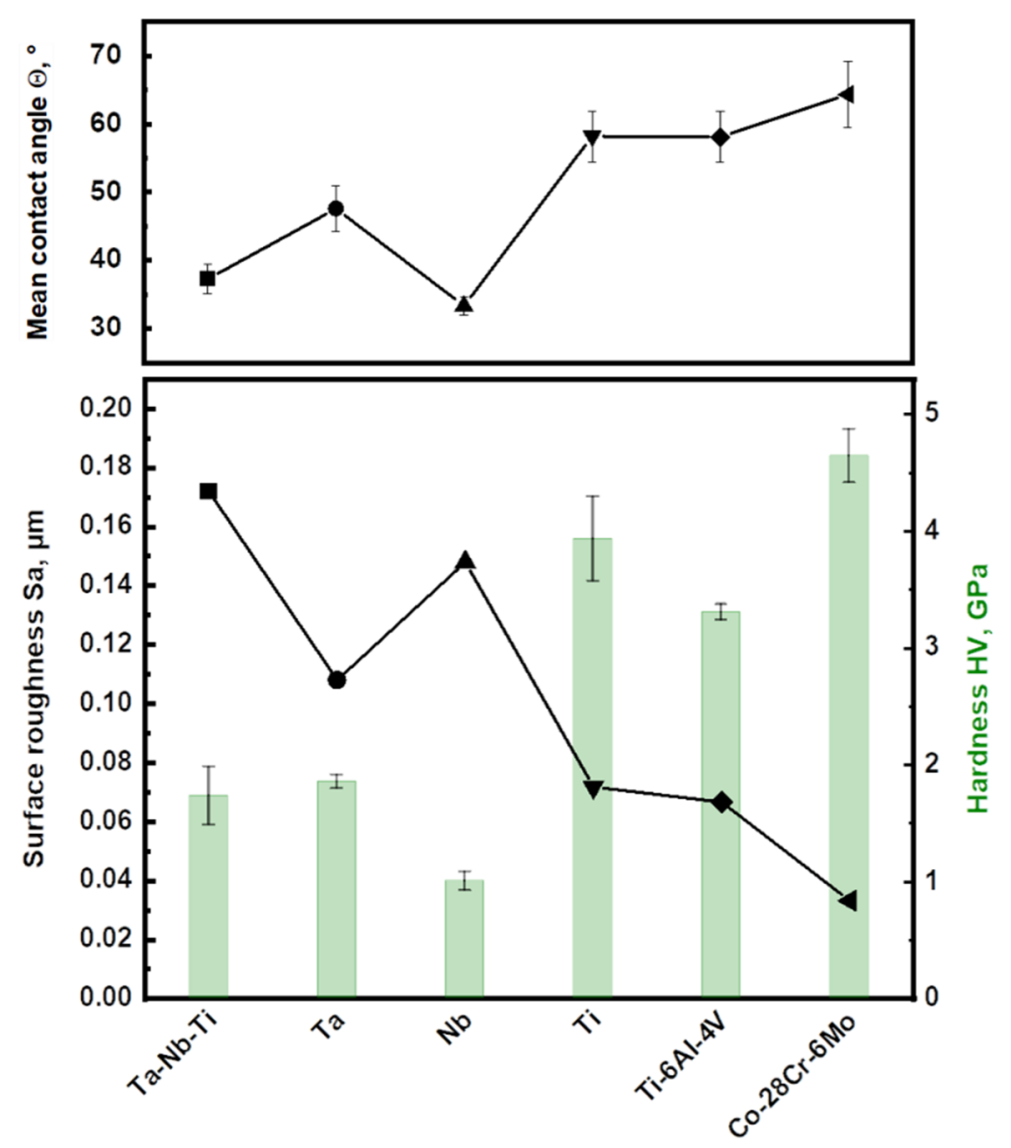

Figure 5. Presentation of the obtained surface parameters (surface roughness Sa and mean contact angle) in comparison with the microhardness analysis of the equiatomic alloy $\mathrm{Ta}-\mathrm{Nb}$ - $\mathrm{Ti}$, the respective elements and other biomedical implant materials.

\subsubsection{Contact Angle and Surface Roughness Analysis}

To validate the surfaces of the samples for biocompatibility testing, different analysis methods were applied. The surface wettability analysis was conducted via contact angle measurements (OCA) on the prepared samples by means of the sessile-drop method. In accordance with DIN EN ISO 19403-2:2020-04 [42], $4 \mu \mathrm{L}$ of water was applied on the sample surface, the drop contour was identified, and the contact angle $\Theta$ was determined using the Young-Laplace-method [43]. Prior to the measurements, the samples were cleaned with ethanol. Tests were repeated 5 times for each sample to obtain a valid statistic. The results are depicted in Figure 5.

The surface roughness of the different specimens were validated using a confocal microscope. The corresponding 3D surface parameters, such as Sa (arithmetic average height), Sz (maximum height), Sv (maximum recess height), etc., were determined according to DIN EN ISO 25178-1:2016-12 [44] and are displayed in Table 2. The arithmetic average height is displayed in Figure 5 as the surface criterion of the samples prepared. The obtained maximum deviation between the sample with the highest surface roughness value $(\mathrm{Ta}-\mathrm{Nb}-\mathrm{Ti}$; $\mathrm{Sa}=0.172 \mu \mathrm{m})$ and the lowest surface roughness value $(\mathrm{Co}-28 \mathrm{Cr}-6 \mathrm{Mo}$; $\mathrm{Sa}=0.033 \mu \mathrm{m})$ was $0.139 \mu \mathrm{m}$. 
Table 2. Contact angles $\Theta$ in water and surface parameters Sa (arithmetic average height), Sz (maximum height) and Sv (maximum recess height) of the samples examined.

\begin{tabular}{ccccc}
\hline Sample & Mean Contact Angle $\boldsymbol{\Theta},^{\circ}$ & Sa, $\boldsymbol{\mu m}$ & Sz, $\boldsymbol{\mu m}$ & Sv, $\boldsymbol{\mu m}$ \\
\hline $\mathrm{Ta}-\mathrm{Nb}-\mathrm{Ti}$ & $37 \pm 2.1$ & 0.172 & 2.48 & 1.41 \\
$\mathrm{Ta}$ & $48 \pm 3.3$ & 0.108 & 1.99 & 1.20 \\
$\mathrm{Nb}$ & $33 \pm 1.3$ & 0.148 & 3.16 & 1.75 \\
$\mathrm{Ti}$ & $58 \pm 3.7$ & 0.079 & 1.20 & 0.52 \\
$\mathrm{Ti}-6 \mathrm{Al}-4 \mathrm{~V}$ & $58 \pm 3.7$ & 0.067 & 1.50 & 0.65 \\
$\mathrm{Co}-28 \mathrm{Cr}-6 \mathrm{Mo}$ & $64 \pm 4.8$ & 0.033 & 0.32 & 0.18 \\
\hline Mean & $50 \pm 11.4$ & $0.101 \pm 0.4$ & $1.77 \pm 0.9$ & $0.95 \pm 0.5$ \\
\hline
\end{tabular}

When comparing the results of the OCA measurements and the surface roughness of the samples, the following correlation can be identified: Decreasing surface roughness results in an increasing contact angle. As all samples exhibited wettable surfaces $\left(\mathrm{CA}<90^{\circ}\right)$, this observation is based on an increase of surface area due to the rough surface, thus resulting in a better wettability, which is in good agreement with the literature [43]. It must be noted that these findings indicate differences of the samples' surfaces, even though carefully prepared, and an influence on the comparability of the specimen regarding the biocompatibility experiments (cell attachment and spreading) can therefore not be excluded [45].

\subsubsection{Biocompatibility}

To test the potential usability of the novel alloys as an endoprosthetic implant material in an intraosseous application, human osteosarcoma cells (SaOs-2) were incubated on the novel alloy $\mathrm{Ta}-\mathrm{Nb}-\mathrm{Ti}$, as well as on reference elements $\mathrm{Ta}$ and $\mathrm{Nb}$ and samples, which are already used as implant material [46] (Co-28Cr-6Mo, Ti-6Al-4V, and pure Ti). To evaluate the interaction of the osteoblast like cells with the different materials, the attachment and spreading of these cells on the surfaces were investigated. Phalloidin was used to visualize the cytoskeleton. Phalloidin can penetrate the cells and binds with high selectivity to the F-actin of the cytoskeleton. For imaging, the Phalloidin is fluorescently labelled with Alexa Fluor 488, which stains the cytoskeleton of the cell green. Figure 6a depicts the SaOs-2 cells on the different alloys. There is no difference in the number of osteoblasts attached to the different surfaces. Furthermore, the ratio between nucleus and cytoplasm was evaluated to compare the attachment behavior of the cells. Again, there was no difference observed between the alloys tested, indicating no negative effect on the osteoblasts (Figure $6 \mathrm{~b}$ ).

A reaction towards a foreign material in the human body is an unavoidable process that takes place whenever any material is implanted. This reaction is mostly inflammatory (e.g., IL- 6 and TNF- $\alpha$ ) and can develop into a fibrotic response (TGF- $\beta$ and fibronectin) over time [47]. Therefore, in a subsequent step, the inflammatory potential of the novel alloys was tested using a monocytic cell line (MM6). These cells were incubated for $24 \mathrm{~h}$ on the different platelets and the reaction of these cells towards either inflammation (Figure $7 \mathrm{a}-\mathrm{c}$ ) or fibrosis marker genes (Figure $7 \mathrm{~d}, \mathrm{e}$ ) was investigated using qRT-PCR. No significant differences between $\mathrm{Co}-28 \mathrm{Cr}-6 \mathrm{Mo}$, Ti-6Al-4V, pure $\mathrm{Ti}, \mathrm{Ta}$, and $\mathrm{Nb}$ were observed. However, a significant reduced expression of IL-6 ( 20-fold, $p=0.006)$, IL-1 ( 3-fold, $p=0.007)$, and TNF alpha ( 2-fold, $p=0.04)$ was observed comparing alloy Ta-Nb-Ti to the other samples examined. Especially, in comparison to pure Ti or Ti-6Al-4V, alloy Ta-Nb-Ti showed a markedly reduced inflammatory capacity. The most surprising result is that alloy $\mathrm{Ta}-\mathrm{Nb}-\mathrm{Ti}$ seems to be more resistant to inflammation in comparison with the respective elements $\mathrm{Ta}$, $\mathrm{Nb}$, and Ti. No changes in expression were observed with respect to fibrosis markers. 
(a)
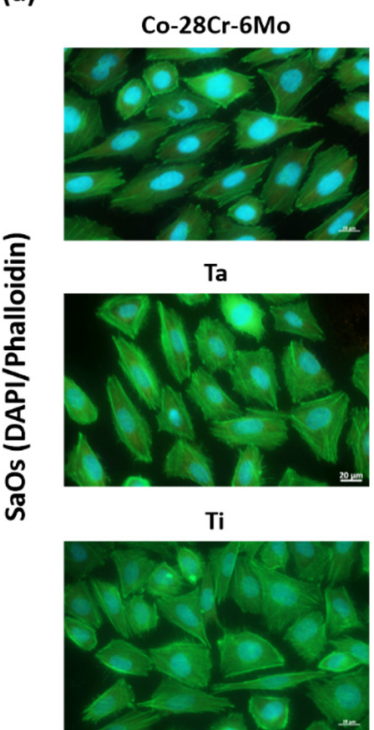

Ti-6Al-4V

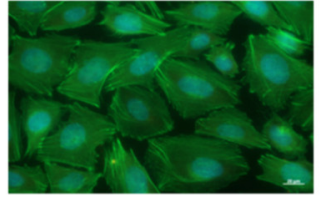

$\mathrm{Nb}$

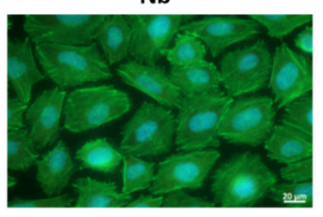

$\mathrm{Ta}-\mathrm{Nb}-\mathrm{Ti}$

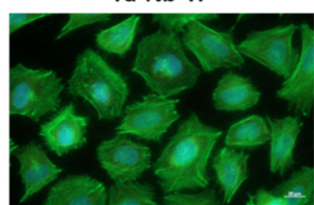

(b)

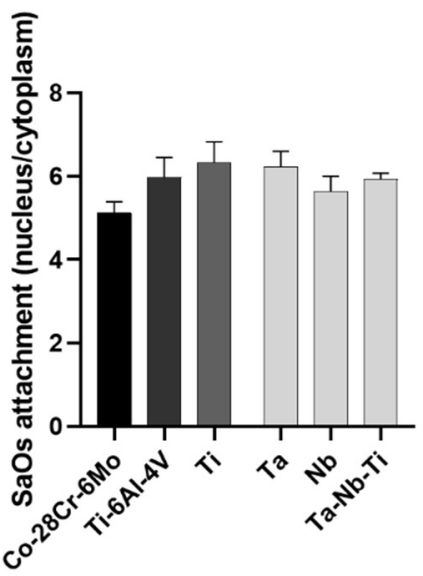

Figure 6. Osteoblast attachment to alloy surfaces. SaOs-2 cells were incubated on samples manufactured from standard implant alloys data from [46] (Co-28Cr-6Mo, Ti-6Al-4V and pure Ti) and compared to elemental $\mathrm{Ta}$ and $\mathrm{Nb}$ and novel alloy Ta-Nb-Ti. (a) Representative pictures of SaOs-2 attachment to the materials after $24 \mathrm{~h}$ (cytoskeleton: green, nucleus: blue). (b) Calculation of nucleus to cytoplasm ratio for the tested alloys (Mean \pm SEM (standard error of mean), $N=3, p=0.4$ using one-way ANOVA (analysis of variance)).

(a)

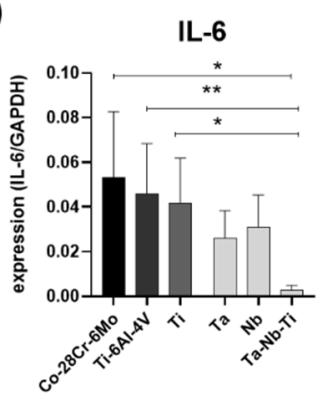

(d)

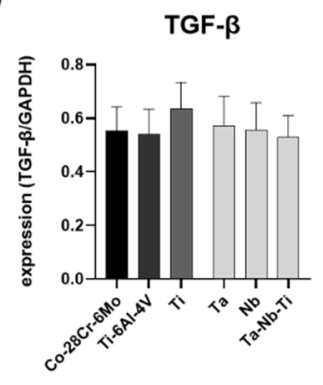

(b)

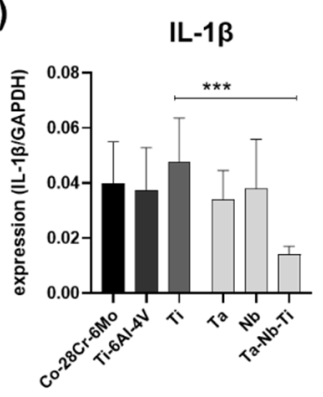

(e)

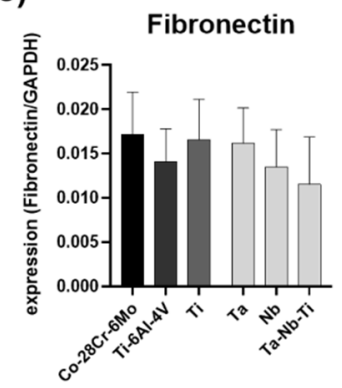

(c)

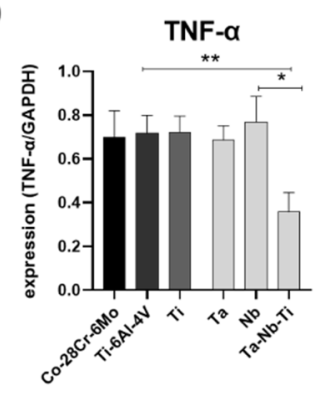

Figure 7. Expression of inflammatory and fibrosis marker genes by monocytes incubated on novel implant alloy Ta-Nb-Ti, compared to standard implant materials data from [46] and elemental Ta and $\mathrm{Nb}$. Quantitative RT-PCR results (a) IL-6 expression on tested implant materials, (b) IL-1ß expression, (c) TNF- $\alpha$ expression, (d) TGF- $\beta$ expression and (e) Fibronectin expression $(N=5)$. GapDH was used as housekeeping. The values are given as mean with SEM and were analyzed for statistical significance using a one-way ANOVA with Dunn's post-hoc test. ${ }^{*} p<0.05 ;{ }^{* *} p<0.01$. 


\section{Conclusions}

In the present manuscript, we report initial findings regarding the development of a novel multi-component $\mathrm{Ta}-\mathrm{Nb}$-Ti alloy for biomedical applications.

The investigations included equiatomic alloy $\mathrm{Ta}-\mathrm{Nb}-\mathrm{Ti}$, as well as several metallic samples made from $\mathrm{Ta}, \mathrm{Nb}$, Ti, Ti-6Al-4V, and $\mathrm{Co}-28 \mathrm{Cr}-6 \mathrm{Mo}$, which were metallographically prepared and examined by means of XRD and SEM analyses.

Furthermore, samples of the aforementioned elements and alloys were prepared with 1200 grit $\mathrm{SiC}$ grinding paper for subsequent cell cultivation experiments.

Validation experiments (contact angle measurements by means of the sessile drop method, confocal microscope surface roughness analysis, and microhardness analysis of the surface) revealed that, even though the samples were prepared cautiously, surface roughness differences are inevitable regarding the sample preparation methods used and an influence regarding cell attachment experiments could therefore not be excluded [45].

Biocompatibility experiments by means of the cultivation of human osteosarcoma cells (SaOs-2) were carried out on all samples. Analysis of the fluorescently labelled osteoblasts indicated no difference between novel alloy $\mathrm{Ta}-\mathrm{Nb}-\mathrm{Ti}$ and the other samples, considering the number of cells, as well as the ratio between nucleus and cytoplasm (cell attachment). Additionally, inflammatory experiments with monocytic cells (MM6) were performed on the samples for $24 \mathrm{~h}$. Results demonstrated comparable expressions of fibrosis markers across all samples tested and significantly reduced inflammatory capacity regarding alloy $\mathrm{Ta}-\mathrm{Nb}-\mathrm{Ti}$ in comparison with the other alloys, although the latter has a higher roughness.

The overall results of the present study indicate a good biocompatibility of the novel alloy Ta-Nb-Ti in comparison with established biomedical materials [46], such as pure $\mathrm{Ti}$, Ti-6Al-4V or Co-28Cr-6Mo, as well as elemental Ta and $\mathrm{Nb}$.

To achieve even more distinguished results in the future, ongoing biocompatibility experiments are focused on sample preparation methodologies regarding the surface quality and comparability (f.e. by means of laser structuring). In addition, the spectrum of OCA analysis will be extended from water to the fluids that are used for cell cultivation experiments (i.e., artificial human body fluids) to obtain more specific contact angles.

Author Contributions: Conceptualization, M.R., G.H. and J.S.; methodology, M.R. and J.B.; validation, M.R., G.H. and J.B.; investigation, M.R. and J.B.; writing-original draft preparation, M.R.; writing-review and editing, G.H., J.S., M.K. and J.B.; supervision, M.K.; project administration, M.K. and J.B. All authors have read and agreed to the published version of the manuscript.

Funding: Financial support of the Methodisch-Diagnostisches Zentrum Werkstoffprüfung (MDZWP) e.V., Magdeburg, Germany and the "Graduiertenförderung Land Sachsen-Anhalt" is greatly acknowledged.

Institutional Review Board Statement: Not applicable.

Informed Consent Statement: Not applicable.

Data Availability Statement: The data that support the findings of this study are available from the corresponding author, upon reasonable request.

Acknowledgments: The authors would like to thank Guido Stiebritz (H.C. Starck Hermsdorf GmbH) for providing us with pure $\mathrm{Ta}$ and $\mathrm{Nb}$ sa mple materials. Furthermore we kindly acknowledge the support from Oliver Michael, Gabriele Ginard and Willert Lindner regarding sample preparation and metallography, as well as Ulf Betke for XRD analysis. Also the excellent contributions to the biocompatibility experiments from Mandy Könnecke are greatly acknowledged.

Conflicts of Interest: The authors declare no conflict of interest.

\section{References}

1. George, E.P.; Curtin, W.A.; Tasan, C.C. High entropy alloys: A focused review of mechanical properties and deformation mechanisms. Acta Mater. 2020, 188, 435-474. [CrossRef]

2. Oliveira, J.P.; Shen, J.; Zeng, Z.; Park, J.M.; Choi, Y.T.; Schell, N.; Maawad, E.; Zhou, N.; Kim, H.S. Dissimilar laser welding of a CoCrFeMnNi high entropy alloy to 316 stainless steel. Scr. Mater. 2022, 206, 114219. [CrossRef] 
3. Wang, Y.; Jin, J.; Zhang, M.; Liu, F.; Wang, X.; Gong, P.; Tang, X. Influence of plastic deformation on the corrosion behavior of CrCoFeMnNi high entropy alloy. J. Alloys Compd. 2022, 891, 161822. [CrossRef]

4. Tsai, M.H.; Yeh, J.W. High-entropy alloys: A critical review. Mater. Res. Lett. 2014, 2, 107-123. [CrossRef]

5. Gao, M.C.; Liaw, P.K.; Yeh, J.W.; Zhang, Y. High-Entropy Alloys: Fundamentals and Applications; Springer International Publishing: Cham, Switzerland, 2016.

6. Ching, W.Y.; San, S.; Brechtl, J.; Sakidja, R.; Zhang, M.; Liaw, P.K. Fundamental electronic structure and multiatomic bonding in 13 biocompatible high-entropy alloys. npj Comput. Mater. 2020, 6, 45. [CrossRef]

7. Castro, D.; Jaeger, P.; Baptista, A.C.; Oliveira, J.P. An overview of high-entropy alloys as biomaterials. Metals 2021, 11, 648. [CrossRef]

8. Yan, X.H.; Ma, J.; Zhang, Y. High-throughput screening for biomedical applications in a Ti-Zr-Nb alloy system through masking co-sputtering. Sci. China Phys. Mech. Astron. 2019, 62, 996111. [CrossRef]

9. Andersen, P.J. Metals for Use in Medicine. In Comprehensive Biomaterials II; Elsevier: Amsterdam, The Netherlands, 2017; Volume 1, pp. 1-18.

10. Kuhn, L.T. Biomaterials. In Introduction to Biomedical Engineering; Elsevier: Amsterdam, The Netherlands, $2012 ;$ pp. $219-271$.

11. Siswomihardjo, W. Advanced Structured Materials. In Biomaterials and Medical Devices; Mahyudin, F., Hermawan, H., Eds.; Springer International Publishing: Cham, Switzerland, 2016; Volume 58.

12. Wilson, J. Metallic biomaterials. In Fundamental Biomaterials: Metals; Elsevier: Amsterdam, The Netherlands, 2018; pp. 1-33.

13. Wintermantel, E.; Ha, S.-W. (Eds.) Medizintechnik; Springer: Berlin/Heidelberg, Germany, 2009.

14. Regenberg, M.; Hasemann, G.; Wilke, M.; Halle, T.; Krüger, M. Microstructure Evolution and Mechanical Properties of Refractory Mo-Nb-V-W-Ti High-Entropy Alloys. Metals 2020, 10, 1530. [CrossRef]

15. Shi, Y.; Yang, B.; Liaw, P.K. Corrosion-resistant high-entropy alloys: A review. Metals 2017, 7, 43. [CrossRef]

16. Shittu, J.; Pole, M.; Cockerill, I.; Sadeghilaridjani, M.; Reddy, L.V.K.; Manivasagam, G.; Singh, H.; Grewal, H.S.; Arora, H.S.; Mukherjee, S. Biocompatible High Entropy Alloys with Excellent Degradation Resistance in a Simulated Physiological Environment. ACS Appl. Bio Mater. 2020, 3, 8890-8900. [CrossRef]

17. Yan, X.; Zhang, Y. A body-centered cubic $\mathrm{Zr}_{50} \mathrm{Ti}_{35} \mathrm{Nb}_{15}$ medium-entropy alloy with unique properties. Scr. Mater. 2020, 178, 329-333. [CrossRef]

18. Todai, M.; Nagase, T.; Hori, T.; Matsugaki, A.; Sekita, A.; Nakano, T. Novel TiNbTaZrMo high-entropy alloys for metallic biomaterials. Scr. Mater. 2017, 129, 65-68. [CrossRef]

19. Iijima, Y.; Nagase, T.; Matsugaki, A.; Wang, P.; Ameyama, K.; Nakano, T. Design and development of Ti-Zr-Hf-Nb-Ta-Mo high-entropy alloys for metallic biomaterials. Mater. Des. 2021, 202, 109548. [CrossRef]

20. Motallebzadeh, A.; Peighambardoust, N.S.; Sheikh, S.; Murakami, H.; Guo, S.; Canadinc, D. Microstructural, mechanical and electrochemical characterization of TiZrTaHfNb and $\mathrm{Ti}_{1.5} \mathrm{ZrTa}_{0.5} \mathrm{Hf}_{0.5} \mathrm{Nb}_{0.5}$ refractory high-entropy alloys for biomedical applications. Intermetallics 2019, 113, 106572. [CrossRef]

21. Habashi, F. Historical introduction to refractory metals. Miner. Procesing Extr. Metall. Rev. 2001, 22, 25-53. [CrossRef]

22. Yuan, Y.; Wu, Y.; Yang, Z.; Liang, X.; Lei, Z.; Huang, H.; Wang, H.; Liu, X.; An, K.; Wu, W.; et al. Formation, structure and properties of biocompatible TiZrHfNbTa high-entropy alloys. Mater. Res. Lett. 2019, 7, 225-231. [CrossRef]

23. Geanta, V.; Voiculescu, I.; Vizureanu, P.; Victor Sandu, A. High Entropy Alloys for Medical Applications. In Engineering Steels and High Entropy-Alloys; IntechOpen: London, UK, 2020; pp. 4-12.

24. Hasegawa, M. Thermodynamic Basis for Phase Diagrams. In Treatise on Process Metallurgy; Elsevier: Amsterdam, The Netherlands, 2014; Volume 1, pp. 527-556.

25. Yeh, J.W.; Chen, S.K.; Lin, S.J.; Gan, J.Y.; Chin, T.S.; Shun, T.T.; Tsau, C.H.; Chang, S.Y. Nanostructured high-entropy alloys with multiple principal elements: Novel alloy design concepts and outcomes. Adv. Eng. Mater. 2004, 6, 274, 299-303. [CrossRef]

26. Otto, F.; Yang, Y.; Bei, H.; George, E.P. Relative effects of enthalpy and entropy on the phase stability of equiatomic high-entropy alloys. Acta Mater. 2013, 61, 2628-2638. [CrossRef]

27. Yang, X.; Zhang, Y. Prediction of high-entropy stabilized solid-solution in multi-component alloys. Mater. Chem. Phys. 2012, 132, 233-238. [CrossRef]

28. Fang, S.; Xiao, X.; Xia, L.; Li, W.; Dong, Y. Relationship between the widths of supercooled liquid regions and bond parameters of Mg-based bulk metallic glasses. J. Non-Cryst. Solids 2003, 321, 120-125. [CrossRef]

29. Guo, S.; Hu, Q.; Ng, C.; Liu, C.T. More than entropy in high-entropy alloys: Forming solid solutions or amorphous phase. Intermetallics 2013, 41, 96-103. [CrossRef]

30. Wang, Z.; Guo, S.; Liu, C.T. Phase Selection in High-Entropy Alloys: From Nonequilibrium to Equilibrium. Jom 2014, 66, 1966-1972. [CrossRef]

31. Ye, Y.F.; Wang, Q.; Lu, J.; Liu, C.T.; Yang, Y. High-entropy alloy: Challenges and prospects. Mater. Today 2016, 19, 349-362. [CrossRef]

32. Nagase, T.; Todai, M.; Hori, T.; Nakano, T. Microstructure of equiatomic and non-equiatomic Ti-Nb-Ta-Zr-Mo high-entropy alloys for metallic biomaterials. J. Alloys Compd. 2018, 753, 412-421. [CrossRef]

33. Xu, X.; Ward, R.M.; Jacobs, M.H.; Lee, P.D.; McLean, M. Tree-ring formation during vacuum arc remelting of INCONEL 718: Part I. Experimental investigation. Metall. Mater. Trans. A 2002, 33, 1795-1804. [CrossRef] 
34. Xu, X.; Zhang, W.; Lee, P.D. Tree-ring formation during vacuum Arc remelting of INCONEL 718: Part II. Mathematical modeling. Metall. Mater. Trans. A 2002, 33, 1805-1815. [CrossRef]

35. Pešáková, V.; Kubies, D.; Hulejová, H.; Himmlová, L. The influence of implant surface properties on cell adhesion and proliferation. J. Mater. Sci. Mater. Med. 2007, 18, 465-473. [CrossRef]

36. Zareidoost, A.; Yousefpour, M.; Ghasemi, B.; Amanzadeh, A. The relationship of surface roughness and cell response of chemical surface modification of titanium. J. Mater. Sci. Mater. Med. 2012, 23, 1479-1488. [CrossRef]

37. Crackau, M.; Harnisch, K.; Baierl, T.; Rosemann, P.; Lohmann, C.H.; Bertrand, J.; Halle, T. Microstructure and surface investigations of TiAl6V4 and CoCr28Mo6 orthopaedic femoral stems. In IOP Conference Series: Materials Science and Engineering; IOP Publishing: Bristol, UK, 2020; Volume 882.

38. Jayaraman, M.; Meyer, U.; Bühner, M.; Joos, U.; Wiesmann, H.P. Influence of titanium surfaces on attachment of osteoblast-like cells in vitro. Biomaterials 2004, 25, 625-631. [CrossRef]

39. Dolgov, N.A.; Dikova, T.; Dzhendov, D.; Pavlova, D.; Simov, M. Mechanical Properties of Dental Co-Cr Alloys Fabricated via Casting and Selective Laser Melting. Mater. Sci. Non-Equilib. Phase Transform. 2016, 2, 3-7.

40. Barreda, J.L.; Santamaría, F.; Azpiroz, X.; Irisarri, A.M.; Varona, J.M. Electron beam welded high thickness Ti6Al4V plates using filler metal of similar and different composition to the base plate. Vacuum 2001, 62, 143-150. [CrossRef]

41. Boyer, R.; Welsch, G.; Collings, E.W. Materials Properties Handbook: Titanium Alloys; ASM International: Almere, The Netherlands, 1994; ISBN 9780871704818.

42. DIN DIN EN ISO 19403-2:2020-04 Beschichtungsstoffe-Benetzbarkeit-Teil 2: Bestimmung der Freien Oberflächenenergie Fester Oberflächen durch Messung des Kontaktwinkels; Beuth Verlag GmbH: Berlin, Germany, 2020; p. 21.

43. Law, K.Y.; Zhao, H. Surface Wetting: Characterization, Contact Angle, and Fundamentals; Springer International Publishing: Basel, Switzerland, 2015.

44. DIN DIN EN ISO 25178-1:2016-12 Geometrische Produktspezifikation (GPS)-Oberflächenbeschaffenheit: Flächenhaft-Teil 1: Angabe von Oberflächenbeschaffenheit (ISO 25178-1:2016); Beuth Verlag GmbH: Berlin, Germany, 2016; p. 36.

45. Boyan, B.D.; Lohmann, C.H.; Dean, D.D.; Sylvia, V.L.; Cochran, D.L.; Schwartz, Z. Mechanisms Involved in Osteoblast Response to Implant Surface Morphology. Annu. Rev. Mater. Res. 2001, 31, 357-371. [CrossRef]

46. Chopplet, M.; Theirry, J.P. Biomedical Materials; Springer: Berlin/Heidelberg, Germany, 1990; Volume 5, ISBN 9783030492052.

47. Carnicer-Lombarte, A.; Chen, S.T.; Malliaras, G.G.; Barone, D.G. Foreign Body Reaction to Implanted Biomaterials and Its Impact in Nerve Neuroprosthetics. Front. Bioeng. Biotechnol. 2021, 9, 622524. [CrossRef] [PubMed] 